\title{
ОЦЕНКА КОМПОЗИЦИОННОГО СОСТАВА ТЕЛА И ОСНОВНОГО ОБМЕНА У ДЕВОЧЕК ПОДРОСТКОВ С ОЖИРЕНИЕМ И ГИПЕРАНДРОГЕНИЕЙ, ОБУСЛОВЛЕННОЙ ФОРМИРУЮЩИМСЯ СИНДРОМОМ ПОЛИКИСТОЗНЫХ ЯИЧНИКОВ
}

\author{
Окороков П.Л., Нагаева Е.В., Васюкова О.В. \\ ФГБУ «НМИЦ эндокринологии» Минздрава России
}

Одной из наиболее частых причин нарушений менструального цикла у девочек подростков с ожирением является формирование синдрома поликистозных яичников (СПЯ) и развитие гиперандрогении. Основным методом лечения данного состояния является снижение массы тела. Тестостерон обладает анаболическим действием, а гиперандрогения, развивающаяся при СПЯ, может влиять на композиционный состав тела, потенцируя увеличение количества тощей и в особенности, скелетной мышечной массы в организме. Тощая масса является ключевым фактором, определяющим основной обмен, снижение интенсивности которого может предрасполагать к прогрессированию ожирения.

Цель работы: оценить влияние гиперандрогении на композиционный состав тела и уровень основного обмена у девочек подростков с ожирением и формирующимся синдромом поликистозных яичников.

Материалы и методы: обследовано 53 девочки в возрасте от 14 до 17,5 лет (средний возраст 15,7 $\pm 1,5$ лет) с конституционально-экзогенным ожирением - SDS ИМТ 3,15 \pm 0,47, разделенные на 2 группы, в зависимости от наличия формирующегося СПЯ. Диагноз формирующегося СПЯ устанавливался при сочетании нарушений менструального цикла с повышением общего тестостерона сыворотки и/или увеличением объема яичников $>10$ мл по данным УЗИ малого таза. В первую группу (с

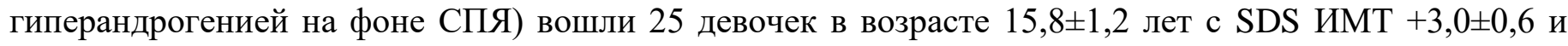

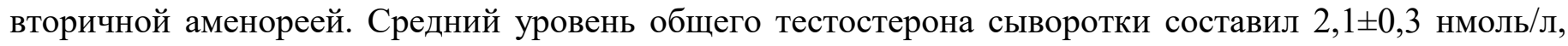
средний объем яичников $-11,3 \pm 1,1 \mathrm{~cm}^{3}$. Контрольную группу (n=28) составили девочки с ожирением без нарушений менструального цикла, сопоставимые с исследуемой группой по SDS ИМТ и возрасту, но различающиеся по уровню общего тестостерона $(\mathrm{p}<0,01)$. Всем девочкам проведена оценка основного обмена методом непрямой респираторной калориметрии (метаболограф Quark RMR) и биоимпедансный анализ состава тела.

Результаты: Количество тощей массы у подростков с ожирением и гиперандрогенией на фоне формирующегося СПЯ было сопоставимо с группой контроля $(57,2 \pm 5,7$ vs $56,9 \pm 5,7$ \%; p=0,78). Сравнение количества скелетной мышечной массы $(23,1 \pm 5,1$ vs $23,5 \pm 1,5 \%$ ) и ее доли в тощей массе $(43,1 \pm 2,8$ vs $42,1 \pm 3,9 \%)$ в исследуемых группах также не выявило существенных различий (p $>0,05)$. Абсолютные значения основного обмена в исследуемых группах были сопоставимы (1884 vs 1894 ккал/сутки; $\mathrm{p}=0,84)$. Корреляционный анализ не выявил взаимосвязей общего тестостерона сыворотки с параметрами композиционного состава тела и уровнем основного обмена как в группе подростков с гиперандрогенией и формирующимся СПЯ, так и в контрольной группе.

Заключение: Гиперандрогения не влияет на параметры композиционного состава тела и уровень основного обмен у девочек подростков с ожирением и формирующимся синдромом поликистозных яичников.

Ключевые слова: ожирение, дети, синдром поликистозных яичников, основной обмен, биоимпедансный анализ 